Thorax (1976), 31, 320.

\title{
Cardiovascular depressant effect of protamine sulphate: experimental study and clinical implications
}

\author{
MONEIMA. FADALI, CHARLESA. PAPACOSTAS, \\ JAMES J. DUKE, MARK LEDBETTER, and \\ M A R Y O B A K K E N
}

\begin{abstract}
Department of Surgery, Section of Thoracic and Cardiac Surgery, and Department of Pharmacology, Temple University Health Sciences Center, Philadelphia, Pennsylvania, USA
\end{abstract}

Fadali, M. A., Papacostas, C. A., Duke, J. J., Ledbetter, M., and Osbakken, Mary (1976). Thorax, 31, 320-323. Cardiovascular depressant effect of protamine sulphate: experimental study and clinical implications. The mechanisms underlying protamine-induced hypotension and bradycardia were the subject of this investigation. Six groups of dogs with intact circulation were tested in controlled circumstances with various drugs. The following parameters were observed: femoral arterial pressure, central venous pressure, left ventricular pressure and its rate of rise, left ventricular contractile element velocity of shortening, maximal Vce, and cardiac output. The six groups were studied under these pharmacological conditions: ganglionic and adrenal medullary block with hexamethonium chloride, postganglionic parasympathetic blockade by atropine sulphate, alpha and beta adrenergic receptor block by phenoxybenzamine and propranolol respectively, and depletion of endogenous histamine by compound 48/80 (a condensation product of p-methoxyphenethyl methylamine with formaldehyde). The last group was put on extracorporeal circulation to isolate the vascular tree from the heart. The effect of the drug on this isolated vasculature was observed by recording the femoral arterial pressure.

Our findings show that the hypotension and bradycardia are produced by a direct effect of protamine on the myocardium and peripheral vascular system.

Heparin is necessary for the performances of extracorporeal circulation. Protamine sulphate is used to neutralize heparin at the completion of cardiopulmonary bypass (Hurt et al., 1956). Hypotension and bradycardia, the common side effects of protamine, can be detrimental to postcardiotomy patients (Jaques, 1949; Egerton and Robinson, 1961). The mechanism of action of protamine on the intact cardiovascular system and isolated peripheral vasculature has been investigated and is the subject of this paper.

\section{METHODS}

A total of 40 adult mongrel dogs weighing 14 to $23 \mathrm{~kg}$ were divided into seven groups. Six groups (A-F) of six dogs each had intact circulations, and the seventh group $(G)$ of four dogs was put on total cardiopulmonary bypass. All dogs weres anaesthetized with thiopental sodium, intubate and ventilated by a Harvard mechanical respirator DOGS WITH INTACT CIRCULATIONS In groups A-伿 a transsternal incision through the left fifth and right fourth interspaces was used to expose the heart. An electromagnetic flow probe (Statham was placed around the ascending aorta to measure cardiac output (CO). Polyethylene catheters were $e^{+}$ introduced into the left ventricular cavity, left femoral artery, and left femoral vein to measure left ventricular pressure (LVP), its rate of rise (dp/dt), the femoral arterial pressure (FAP), an central venous pressure (CVP) respectively. The left ventricular contractile element velocity (Vce) was determined from isovolumic pressure (IP) and 
$\mathrm{dp} / \mathrm{dt}$; maximal Vce (V max) was obtained by construction of an IP to Vce curve and extrapolation to zero load (Mason, Spann, and Zelis, 1970). Electrocardiograms were always recorded.

Each animal in groups A-F received intravenous heparin, $5 \mathrm{mg} / \mathrm{kg}$, followed by protamine sulphate, $10 \mathrm{mg} / \mathrm{kg}$. Group A animals had both carotid arteries exposed and clamped proximal to the sinus region to test the carotid sinus reflex after heparin-protamine administration. Groups B-F were pretreated intravenously with these drugs: group $\mathbf{B}$ was given hexamethonium chloride, $10 \mathrm{mg} / \mathrm{kg}$, to block the autonomic ganglia and epinephrine release by the adrenal medulla. Group C received atropine sulphate, $0.5 \mathrm{mg} / \mathrm{kg}$, to block postganglionic parasympathetic receptors (vagal block). Norepinephrine, $2 \mu \mathrm{g} / \mathrm{kg}$, was given after 10 minutes to test the vagal block. Ordinarily, an increase in blood pressure would be followed by reflex bradycardia; however, an atropinized dog would have no refiex bradycardia following an increased blood pressure. Group D dogs were given phenoxybenzamine (Dibenzyline) $5 \mathrm{mg} / \mathrm{kg}$ and a 30-minute waiting period to achieve complete alpha blockade. In group $\mathrm{E}$, propranolol (Inderal), $1 \mathrm{mg} / \mathrm{kg}$, was given with a 10-minute waiting period for complete sympathetic beta blockade. Group F dogs were given compound 48/80 (a condensation product of $p$ methoxyphenethyl methylamine with formaldehyde), $0.1 \mathrm{mg} / \mathrm{kg}$, slowly over a period of 20 minutes to deplete endogenous histamine (Paton, 1951; Papacostas, Loew, and West, 1959). Before and after heparin-protamine administration the blood $\mathrm{pH}$ was tested in one animal of each group.

The four dogs in group $G$ were cannulated and put on extracorporeal circulation. The heart was isolated by clamping the ascending aorta and pulmonary artery. The effect of protamine on the vascular tree was measured by observing the FAP before and after injection of $10 \mathrm{mg} / \mathrm{kg}$ of protamine into the arterial inflow of the extracorporeal pump.

\section{RESULTS}

The results are summarized in the Table. Group A dogs receiving no premedication had an appreciable reduction of all measured indices: a mean drop of $39 \%$ in mean FAP, $44 \%$ in IP, $38 \%$ in $\mathrm{dp} / \mathrm{dt}, 31 \%$ in Vmax, and $33 \%$ in CO. These reduced values were noted in every animal and were statistically significant. Simultaneous bilateral clamping of the carotid arteries proximal to the carotid sinus reversed the hypotensive bradycardic effect of protamine in all six dogs. However, the hypotension and bradycardia recurred after removing the clamps.

Medication with hexamethonium in group B, atropine in group $C$, phenoxybenzamine in group $\mathrm{D}$, propranolol in group $\mathrm{E}$, and compound $48 / 80$ in group $F$ failed to abolish or reverse the protamine effects noted in control animals, group A. In each group shown in the Table the mean decreases are reproducible and significantly differ from zero. The small differences among the mean percentage decreases for FAP in the six groups just met statistical significance at the $5 \%$ level but were not clinically important (one-way analysis of variance applied to logarithms). Differences among the mean percentage decreases in CO, IP, $\mathrm{dp} / \mathrm{dt}$, and Vmax were smaller and of no statistical significance.

In group $\mathbf{G}$ animals with isolated peripheral vasculature, protamine continued to reduce FAP at an average of $24 \%$ which is similar to that in the other groups.

In all seven groups there were no significant pH changes after heparin-protamine administration.

\section{DISCUSSION}

The mechanism responsible for the hypotensive and bradycardic effects of protamine sulphate remains a controversial topic. To answer some of these questions the clinical situation was simulated in dogs by giving the heparin followed by pro-

T A B L E

MEAN PERCENTAGE CHANGE IN DIFFERENT PARAMETERS FOLLOWING HEPARIN.PROTAMINE ADMINISTRATION IN SEVEN ANIMAL GROUPS

\begin{tabular}{|c|c|c|c|c|c|c|c|}
\hline & Group A & Group B & Group C & Group D & Group E & Group F & Group G \\
\hline $\begin{array}{l}\text { Premedication } \\
\text { Mean FAP }(\mathrm{mmHg}) \\
\text { IP }(\mathrm{mmHg}) \\
\mathrm{dp} / \mathrm{dt} \\
\mathrm{V} \max (\mathrm{ml} / \mathrm{sec}) \\
\mathrm{CO}(\mathrm{ml} / \mathrm{min})\end{array}$ & $\begin{array}{l}\text { None } \\
-39 \\
-44 \\
-38 \\
-31 \\
-33\end{array}$ & $\begin{array}{c}\text { Hexa- } \\
\text { methonium } \\
-24 \\
-33 \\
-32 \\
-27 \\
-26\end{array}$ & $\begin{array}{l}\text { Atropine } \\
\begin{array}{r}-29 \\
-42 \\
-40 \\
-33 \\
-29\end{array}\end{array}$ & $\begin{array}{c}\text { Phenoxy- } \\
\text { benzamine } \\
-29 \\
-38 \\
-36 \\
-27 \\
-28\end{array}$ & $\begin{array}{c}\text { Propranolol } \\
-31 \\
-30 \\
-45 \\
-30 \\
-32\end{array}$ & $\begin{array}{c}\text { Compound } \\
\begin{array}{c}48 / 80 \\
-25 \\
-41 \\
-41 \\
-27 \\
-32\end{array}\end{array}$ & 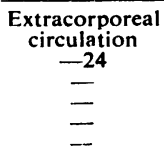 \\
\hline
\end{tabular}


tamine., Group A animals tested the concept of neurogenic reflex by some authors (Egerton and Robinson, 1961; Minker and Koltai, 1964). Proximal carotid artery clamping reversed the hypotension and bradycardia produced by protamine which attests to the integrity of the carotid sinus reflex mediated by autonomic pathways. To test further the neurogenic reflex concept different steps of the autonomic pathways were blocked through premedication. In group B, the autonomic ganglia and the adrenal medulla were blocked by hexamethonium chloride. The femoral arterial pressure, left ventricular pressure, its rate of rise, isovolumic pressure, maximal left ventricular contractile element velocity, and cardiac output were substantially reduced following protamine administration, a response similar to that in dogs with intact ganglia (group A). Thus protamine does not produce its cardiovascular effects through blocking the autonomic ganglia. Atropine sulphate was used to block postganglionic parasympathetic receptors in group $\mathrm{C}$ dogs to eliminate possible reflex cholinergic effect of protamine. Again, as in group $\mathrm{A}$, the animals showed hypotension and depression of myocardial contractility when protamine was given. Alpha blockade by phenoxybenzamine in group $\mathrm{D}$ and beta blockade by propranolol in group $E$ both failed to avert the hypotension and bradycardia after protamine injection. The findings in groups A-E do not support the involvement of neurogenic reflexes or adrenergic receptors in protamine-induced hypotension and bradycardia.

Sensitivity and histamine release due to protamine was proposed by Shelley, Hodgkins, and Visscher (1942). Kern and Langner (1939) could not produce protamine sensitivity in guinea-pigs despite several intraperitoneal injections. Jaques (1949) found that histamine-free protamine preparations could still elicit hypotension. Presently, depletion of endogenous histamine was produced in group $\mathrm{F}$ dogs by premedication with compound $48 / 80$. The hypotension and bradycardia was again elicited following protamine injection. This reinforces the findings of Jaques (1949) and Kern and Langner (1939) that histamine has no significant etiological role in these effects of protamine.

Myocardial contractility depression following protamine administration was demonstrated by Goldman, Joison, and Austen (1969) but disputed by Gourin et al. (1971a), who even advocated an inotropic effect of the drug on dog's myocardium. By estimating the maximal velocity of left ventricular contractile element shortening, the contractile state of an intact heart can be quanti- tated. The techniques of Mason et al. (1970) were? used in the present study, and the maxima velocity was computed from the instantaneou $\overline{\overline{8}}$ correlation of the rate of pressure developed in the left ventricular cavity during the isovolumio phase of contraction. All animals in groups A-F showed a marked decrease in myocardia $\$$ contractility after protamine injection.

The findings in group $G$ provided furthe evidence for the direct effect of protamine on thक्ष vascular tree. Protamine administration into the arterial inflow of the extracorporeal circulation was followed by a significant drop of femorat arterial pressure.

Acid-base changes are not involved because no significant $\mathrm{pH}$ changes were recorded after heparin-protamine injection.

From the results we conclude that the cardio vascular responses to protamine sulphate. administration are due to a direct effect of the drug on the myocardium and vasculature.

This experimental conclusion was clinicall: applied to our patients receiving protamine in fusion at the termination of cardiopulmonar bypass. To prevent hypotension, the followin measures were successful in the majority of cases: $:$ (1) Administration of inotropic agents, it $\vec{B}$ particular calcium chloride or calcium gluconate $\overline{\$}$ isoproterenol or epinephrine to patients without serious tachycardia or significant arrhythmias? Norepinephrine might be used since it reverses the peripheral vasodilating effects of protamine witho out producing tachycardia. (2) If central venous and left atrial pressures permit, a fluid load iक administered to compensate for the expandect capacity of the vascular tree.

We are grateful to Dr. Stanley Schor (Ph.D.), chie and professor, Department of Biometrics, Temples University Health Sciences Center, for the statistica互. analyses.

Support for this work was received partly from the Department of Surgery, Temple University Healtis Sciences Center.

\section{REFERENCES}

Egerton, W. S. and Robinson, C. L. N. (1961). The anti-heparin, anticoagulant and hypotensive pro perties of hexadimethrine and protamine. Lancet 2, 635 .

Goldman, B. S., Joison, J., and Austen, W. G. (1969)尽 Cardiovascular effects of protamine sulfate Annals of Thoracic Surgery, 7, 459.

Gourin, A., Streisand, R. L., Greineder, J. K., andB Stuckey, J. H. (1971a). Protamine sulfate admin 
istration and the cardiovascular system. Journal of Thoracic and Cardiovascular Surgery, 62, 193.

_, _ and Stuckey, J. H. (1971b). Total cardiopulmonary bypass, myocardial contractility, and the administration of protamine sulfate. Journal of Thoracic and Cardiovascular Surgery, 61, 160.

Hurt, R., Perkins, H. A., Osborn, J. J., and Gerbode, F. (1956). The neutralization of heparin by protamine in extracorporeal circulation. Journal of Thoracic and Cardiovascular Surgery, 32, 612.

Jaques, L. B. (1949). A study of the toxicity of the protamine, salmine. British Journal of Pharmacology, 4, 135.

Kern, R. A. and Langner, P. H. (1939). Protamine and allergy. Journal of the American Medical Association, 113, 198.

Mason, D. T., Spann, J. F., Jr., and Zelis, R. (1970). Quantification of the contractile state of the intact human heart. American Journal of Cardiology, 26, 248.
Minker, E. and Koltai, M. (1964). Effect of protamine sulphate on the transmission processes in peripheral sympathetic ganglia. Acta Physiologica Academiae Scientiatum Hungaricae, 24, 365.

Papacostas, C. A., Loew, and West, G. B. (1959). Studies on the toxicity of a histamine liberator, compound 48/80. Archives Internationales de Pharmacodynamies, 120, 353.

Paton, W. D. M. (1951). Compound 48/80: A potent histamine liberator. British Journal of Pharmacology, 6, 499.

Shelley, W. B., Hodgkins, M. P., and Visscher, M. B. (1942). Studies on the toxicity of protamine. Proceedings of the Society of Experimental Biology and Medicine, 50, 300.

Requests for reprints to: Dr. Moneim A. Fadali, 2661 Locksley Place, Los Angeles, California 90039, USA. 